\title{
Electrochemical Polymerization of 4,4-Dimethyl-2,2'-Bithiophene in Concentrated Polymer Liquid Crystal Solution
}

\author{
Naoto Eguchi, Kohsuke Kawabata, Hiromasa Goto* \\ Faculty of Pure and Applied Sciences, Division of Materials Science, University of Tsukuba, Tsukuba, Japan \\ Email: *gotoh@ims.tsukuba.ac.jp
}

How to cite this paper: Eguchi, N., Kawabata, K. and Goto, H. (2017) Electrochemical Polymerization of 4,4-Dimethyl-2,2'Bithiophene in Concentrated Polymer Liquid Crystal Solution. Journal of Materials Science and Chemical Engineering, 5, 6470.

https://doi.org/10.4236/msce.2017.52007

Received: January 20, 2017

Accepted: February 17, 2017

Published: February 20, 2017

Copyright $\odot 2017$ by authors and Scientific Research Publishing Inc. This work is licensed under the Creative Commons Attribution International License (CC BY 4.0).

http://creativecommons.org/licenses/by/4.0/

\begin{abstract}
Electrochemical polymerization of 4,4'-dimethyl-2,2'-bithiophene (4DMBT) was carried out in a concentrated solution of hydroxypropyl cellulose (HPC) liquid crystal in $N, N$-dimethylformamide. Infrared absorption spectra suggested that the resultant polymer film contains HPC. This study demonstrates an electrochemical preparation of a polymer composite having liquid crystal order. We proposed a helical stacking composite model.
\end{abstract}

\section{Keywords}

Conjugated Polymer, Electrochemical Polymerization, Polymer Liquid Crystal, Hydroxypropyl Cellulose

\section{Introduction}

Polythiophene is one of the most studied conductive polymers and referred to as synthetic metals. 4,4'-Dimethyl-2,2'-bithiophene (4DMBT) is a thiophene derivative having alkyl group [1]-[14]. Electrochemical polymerization of conductive polymers gives high crystalline polymer film, but the control of the morphology is still a developmental issue. To solve this, an employment of template in molecular level is studied. Hydroxypropyl cellulose (HPC) is a cellulose derivative having solubility in water and organic solvents. Previous study indicates that HPC can be used as a template for production of polymers [15]. In this research, we synthesized a poly(4DMBT) (abbreviated as $\mathrm{P}-4 \mathrm{DMBT}$ ) by electrochemical polymerization in concentrated HPC liquid crystal electrolyte solution. HPC liquid crystal solution is prepared by dissolving HPC in $N, N$-dimethylformamide (DMF). The HPC/DMF having small amount of supporting salt shows lyotropic liquid crystallinity at an appropriate concentration. Furthermore, HPC shows cholesteric lyotropic liquid crystalline phase with helical aggregation structure in 
DMF solution. Therefore, liquid crystal HPC can be used as a helical template during electrochemical polymerization. This research performs electrochemical polymerization of $4 \mathrm{DMBT}$ in liquid crystalline HPC solution. Surface observation of the polymer film thus obtained is carried out by polarizing optical microscopy. Measurements of Fourier transforming infrared absorption and UVVIS absorption confirm the chemical structure of the polymer composite film.

\section{Experimental}

\subsection{Materials}

A monomer 4DMBT was previously synthesized [16]. HPC was obtained from Wako Pure Chemical Industries, Ltd. (Japan) and used without further purification. Tetrabutylammonium perchlorate (TBAP) was obtained from Tokyo Chemical Industry (TCI, Japan) and used without further purification. DMF was obtained from Nacalai Tesque, (Japan) and used as received.

\subsection{Synthesis}

Electrochemical polymerization of 4DMBT in HPC was carried out (Figure 1). Constituents of electrolyte solution are shown in Table 1. First, 4DMBT and TBAP (supporting salt) were dissolved in DMF. Next, HPC was added to the solution and stirred mechanically by glass rod at room temperature. After mixing very well, the electrolyte solution was injected into sandwich cell with two ITO glass electrode (ITO = indium tin oxide). The method of sandwich cell polymerization was developed by our group previously. The cell was left for ca. $24 \mathrm{~h}$ at room temperature. Direct current $(\mathrm{dc})$ of $4.0 \mathrm{~V}$ was applied across the cell for 60 min. A thin polymer film (P-4DMBT) was prepared on an anode side electrode. After electrochemical polymerization, the sandwich cell was soaked into the distilled water to remove the residual HPC from the polymer surface. After over 30 min, the cell was disassembled. The polymer film was washed with a sufficient amount of distilled water, and acetone to remove the residual HPC, TBAP and unreacted monomer. The polymer film was dried under atmospheric pressure.

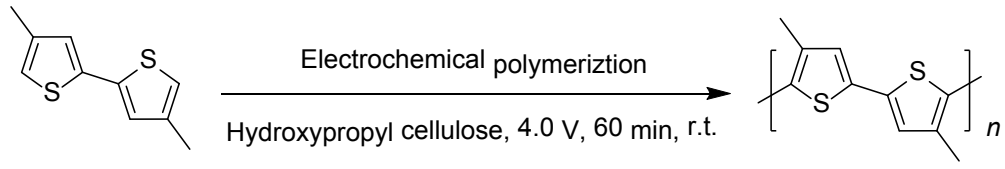

Figure 1. Scheme of electrochemical polymerization of 4,4'-dimethil-2,2'bithiophene (P-4DMBT) in hydroxypropyl cellulose.

Table 1. Constituents of electrolyte solution.

\begin{tabular}{cccc}
\hline & Matrix & Solvent & Supporting salt \\
\cline { 2 - 4 } Monomer & $\mathrm{HPC}^{\mathrm{b}}$ & $\begin{array}{c}N, N \text {-dimethylformamide } \\
(\mathrm{DMF})\end{array}$ & $\begin{array}{c}\left(\mathrm{C}_{4} \mathrm{H}_{9}\right)_{4} \mathrm{~N}^{+} \mathrm{ClO}_{4}{ }^{-} \\
\left(\mathrm{TBAP}^{\mathrm{c}}\right)\end{array}$ \\
\hline $\begin{array}{c}\text { 4DMBT } \\
4.5 \mathrm{mg}\end{array}$ & $700.6 \mathrm{mg}$ & $369.5 \mathrm{mg}$ & $1.1 \mathrm{mg}$ \\
\hline
\end{tabular}

a: 4,4'-dimethyl-2,2'bithiophene; b: $N, N$-dimethylformamide; c: Tetrabutylammonium perchlorate. 


\subsection{Measurements}

Polarizing optical microscopy measurements were carried out by using ECLIPS LV 100 high-resolution polarizing microscope (Nikon). Fourier Transform Infrared absorption spectrum was obtained with a FT-IR 4600 (Jasco) by using the $\mathrm{KBr}$ method. UV-VIS absorption spectroscopy was carried out by using V-630 (Jasco).

\section{Results}

\subsection{Polarizing Optical Microscopy}

The polymer film thus obtained in liquid crystal HPC was examined by polarizing optical microscopy (POM). A POM image of the P-4DMBT is shown in Figure 2. From POM observation, fingerprint like texture derived from cholesteric liquid crystal was confirmed. In this system, HPC/DMF electrolyte solution forms lyotropic cholesteric liquid crystallinity having helical structure at a certain concentration. HPC plays a role of helical template, and transcription of helical structure to the polymer from HPC can be occurred.

\subsection{Fourier Transform Infrared Absorption}

Fourier transform infrared (FT-IR) absorption spectra for HPC, the monomer, and resultant film are shown in Figure 3. Absorption band at $3431 \mathrm{~cm}^{-1}$ is due to hydroxyl group in the pyranose unit of HPC. Absorptions band at $2967 \mathrm{~cm}^{-1}$ and $2932 \mathrm{~cm}^{-1}$ is due to $\mathrm{CH}_{2}$ and $\mathrm{CH}$ stretching vibration. Absorption band at 1533 $\mathrm{cm}^{-1}$ is due to $\mathrm{C}=\mathrm{C}$ stretching vibration. Absorption band at $1079 \mathrm{~cm}^{-1}$ is due to $\mathrm{C}-\mathrm{O}-\mathrm{C}$ stretching vibration. This result revealed that the resultant polymer contains HPC in the film. This is because that the main chain was entangled with HPC during electrochemical polymerization to form helical composite (Figure $4)$.

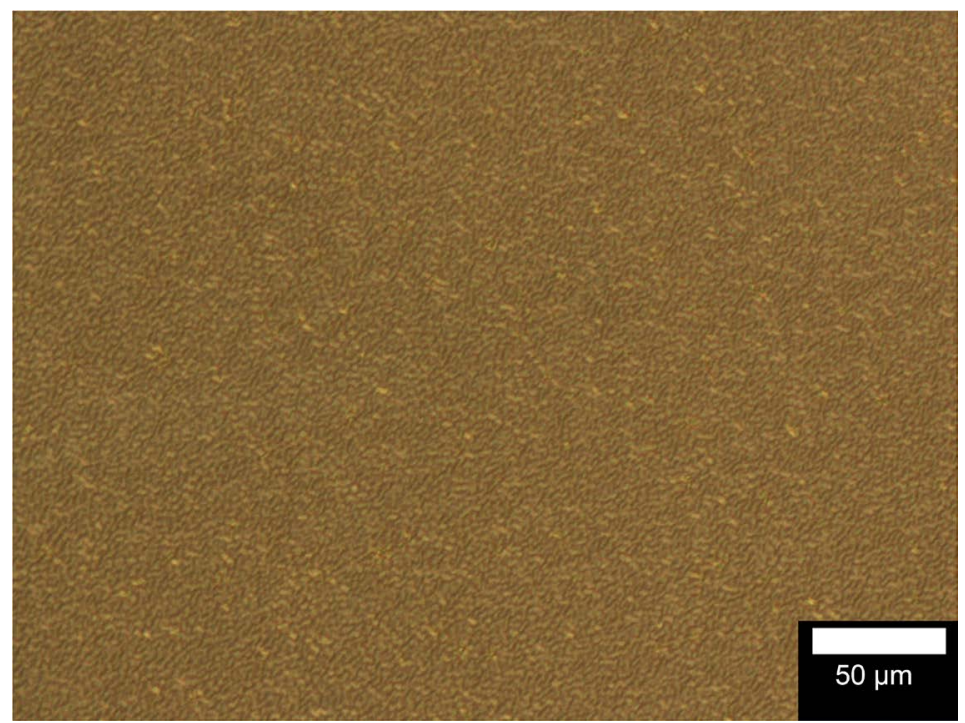

Figure 2. Polarizing optical microscopy image of poly(4,4'-dimethil-2,2'-bithiophene) (P-4DMBT) film. 


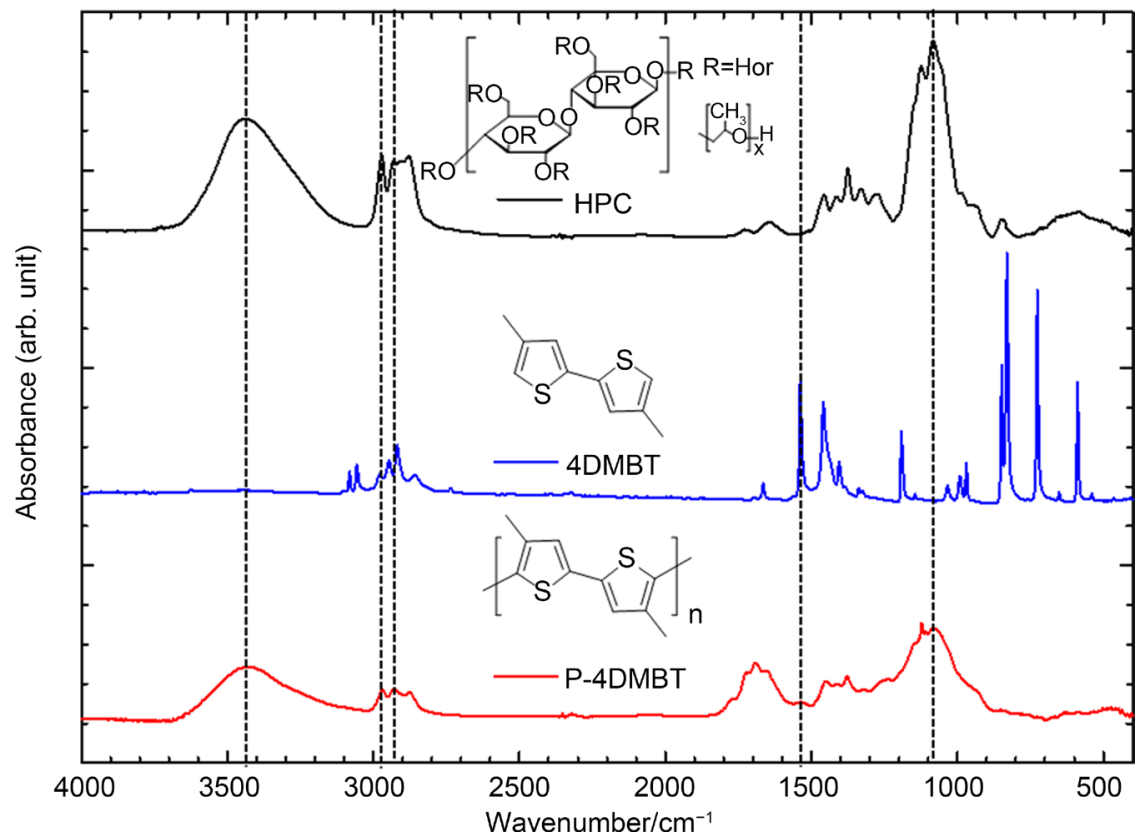

Figure 3. FT-IR spectra of hydroxypropyl cellulose (HPC, black line), 4,4'-dimethyl-2,2'-bithiophene (4DMBT, blue line) and poly(4,4'-dimethyl-2,2'-bithiophene) (P-4DMBT, red line).

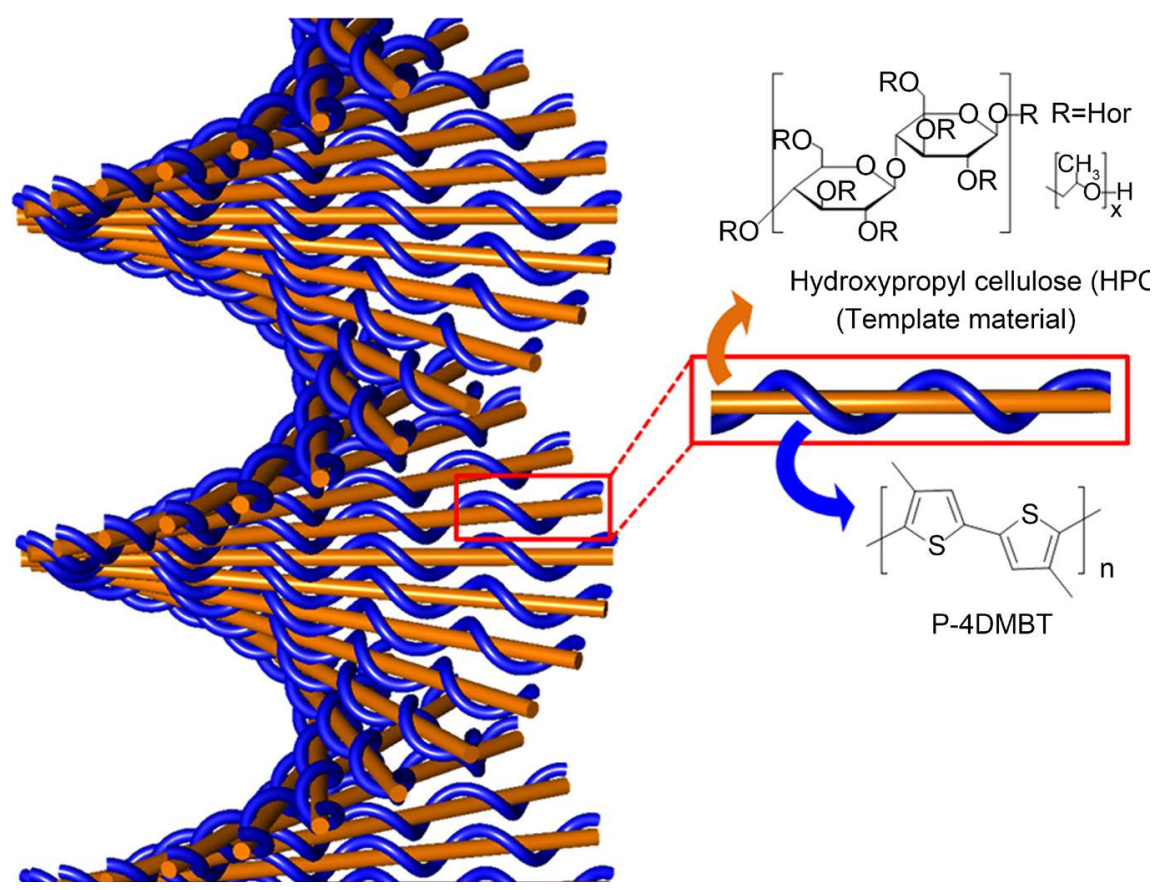

Figure 4. Possible structure of P-4DMBT/HPC composite. HPC (orange rod) and P-4DMBT (blue helical).

\subsection{UV-Vis Absorption}

UV-Vis absorption spectra of P-4DMBT (as prepared film) are shown in Figure 5. An absorption band at $700 \mathrm{~nm}$ is due to polarons, and $>850 \mathrm{~nm}$ is due to bipolarons. A neutral form (reduced form), polarons (radical cations), and bipolarons (dications) are illustrated in Figure 6. As prepared film is a doped form 


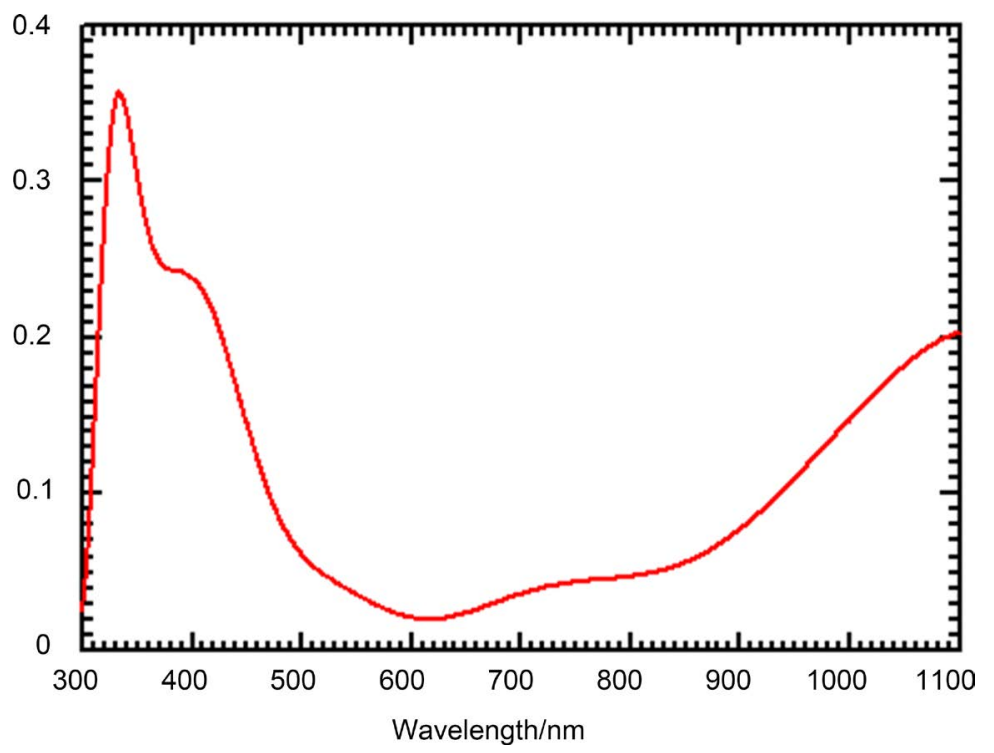

Figure 5. UV-VIS absorption spectra of as prepared P-4DMBT.
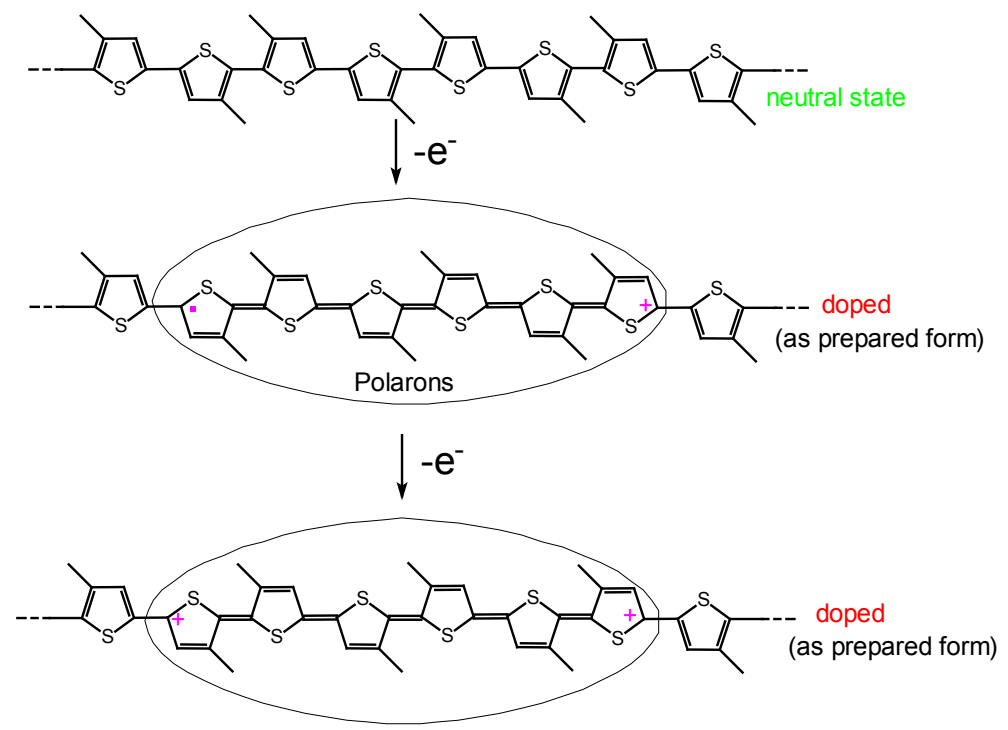

Figure 6. Polarons (radical cations) and bipolarons (dications).

having polarons and bipolarons in the main chain.

The main chain of P-4DMBT is twisted and the charge carriers can be gradually twisted in one handed direction to form helical structure on the cellulose. In this case, the helical charge carriers in the main chain can be referred to as "chiralions" [17]. The chiralions have been found after original development of asymmetric electrochemical polymerization, and liquid crystal solvent asymmetric polymerization [18]. The resultant polymer can be referred to as "helical synthetic metals".

\section{Conclusion}

In this research, electrochemical polymerization of $4 \mathrm{DMBT}$ was carried out in liquid crystal hydroxypropyl cellulose (HPC). The FT-IR absorption spectros- 
copy revealed that the polymer film was to be a composite of P-4DMBT and HPC. The polymer can be entangled in helical manner with HPC in the propagation process in the electrochemical polymerization reaction.

\section{Acknowledgements}

We would like to thank Tsukuba Research Centre for Interdisciplinary Materials Science (TIMS).

\section{References}

[1] Cunningham, D.D., Laguren-Davidson, L., Mark, H.B., Van Pham, C. and Zimmer, H. (1987) Synthesis of Oligomeric 2,5-Thienylenes: Their UV Spectra and Oxidation Potentials. Journal of the Chemical Society, Chemical Communications, 13, 1021-1023. https://doi.org/10.1039/c39870001021

[2] Krische, B., Hellberg, J. and Lilja, C. (1987) Conducting Polymers from Dimethyl-2, 2'-Bithiophenes. Journal of the Chemical Society, Chemical Communications, 19, 1476-1478. https://doi.org/10.1039/C39870001476

[3] Laguren-Davidson, L., Van Pham, C., Zimmer, H., Mark, H.B. and Ondrus, D.J. (1988) Steric Effects on the Controlled Potential Electro-Oxidation of 3-Methylthiophene and Thiophene Oligomers and the Properties of their Polymer Films. Journal of the Electrochemical Society, 135, 1406-1414. https://doi.org/10.1149/1.2096007

[4] Batina, N., Gui, J.Y., Kahn, B.E., Lin, C.H., Lu, F., McCargar, J.W. and Hubbard, A.T. (1989) Studies of Thiophene and Substituted Thiophenes at Platinum(111) Electrodes by Vibrational Spectroscopy and Auger Spectroscopy: Monomers, Dimers, and Polymers. Langmuir, 5, 588-600. https://doi.org/10.1021/la00087a009

[5] Van Pham, C., Burkhardt, A., Shabana, R., Cunningham, D.D., Mark Jr., H.B. and Zimmer, H. (1989) A Convenient Synthesis of 2,5-Thienylene Oligomer: Some of Their Spectroscopic and Electrochemical Properties. Phosphorus, Sulfur, and Silicon and the Related Elements, 46, 153-168. https://doi.org/10.1080/10426508909412061

[6] Barbarella, G., Zambianchi, M. and Bongini, A. (1991) Conformation and Optical Absorption Properties of Thiophene Oligomers: 13C-NMR, UV, and MMP2 Calculations of Di-and Tetramethyl-Quaterthiophenes. Advanced Materials, 3, 494-496. https://doi.org/10.1002/adma.19910031008

[7] Barbarella, G., Bongini, A. and Zambianchi, M. (1992) Synthesis 13C NMR, $\lambda$ Max and MMP2 Calculations of Two "Tailor-Made" $\alpha$-Conjugated Hexamethylsexithiophenes. Tetrahedron, 48, 6701-6708. https://doi.org/10.1016/S0040-4020(01)80015-6

[8] Mastragostino, M., Arbizzani, C., Ferloni, P. and Marinangeli, A. (1992) PolymerBased Electrochromic Devices. Solid State Ionics, 53, 471-478. https://doi.org/10.1016/0167-2738(92)90417-N

[9] Arbizzani, C., Barbarella, G., Bongini, A., Mastragostino, M. and Zambianchi, M. (1992) Electrochemical and Optical Properties of Poly (3-Methylthiophenes) Electrosynthesized by 3,3'-, 3,4'-and 4,4'-Dimethyl-2,2'-Bithiophenes. Synthetic Metals, 52, 329-339. https://doi.org/10.1016/0379-6779(92)90032-E

[10] Distefano, G., Dal Colle, M., Jones, D., Zambianchi, M., Favaretto, L. and Modelli, A. (1993) Electronic and Geometric Structure of Methylthiophenes and Selected Dimethyl-2,2'-Bithiophenes. Journal of Physical Chemistry, 97, 3504-3509. https://doi.org/10.1021/j100116a011 
[11] Arbizzani, C., Barbarella, G., Bongini, A., Mastragostino, M. and Zambianchi, M. (1992) Electrochemical and Optical Properties of Poly (3-Methylthiophenes) Electrosynthesized by 3,3'-, 3,4'- and 4,4'-Dimethyl-2,2'-Bithiophenes. Synthetic Metals, 52, 329-339. https://doi.org/10.1016/0379-6779(92)90032-E

[12] Alemán, C. and Julia, L. (1996) П Conjugation in 2,2'-Bithiophene and Its Dimethyl Derivatives: Model Compounds of Organic Conducting Polymers Based on Thiophene Rings. Journal of Physical Chemistry, 100, 1524-1529.

https://doi.org/10.1021/jp951592o

[13] Tormo, J., Moreno, F.J., Ruiz, J., Fajarí, L. and Juliá, L. (1997) Thallium(III) Trifluoroacetate-Trifluoroacetic Acid in the Chemistry of Polythiophenes. 2. Treatment of 3-Alkylthiophenes and Electron Paramagnetic Resonance Results. Journal of Organic Chemistry, 62, 878-884. https://doi.org/10.1021/jo961065g

[14] Hayashi, N., Murayama, M., Mori, K., Matsuda, A., Chikamatsu, E., Tani, K. and Higuchi, H. (2004) Syntheses and Electronic Properties of the Nickel and Palladium Complexes of the Octaethylporphyrin (M1)-(dihexylbithiophene) n-Octaethylporphyrin (M2) System [OEP (M1)-(DHBTh) n-OEP (M2)] Connected with the Diacetylene Linkage. A Methodology for Molecular Design of the Particular Electronic Structure. Tetrahedron, 60, 6363-6383. https://doi.org/10.1016/j.tet.2004.04.064

[15] Giese, M., Blusch, L.K., Khan, M.K. and MacLachlan, M.J. (2015) Functional Materials from Cellulose-Derived Liquid-Crystal Templates. Angewandte Chemie, 54, 2888-2910. https://doi.org/10.1002/anie.201407141

[16] Kawabata, K., Takeguchi, M. and Goto, H. (2013) Optical Activity of Heteroaromatic Conjugated Polymer Films Prepared by Asymmetric Electrochemical Polymerization in Cholesteric Liquid Crystals: Structural Function for Chiral Induction. Macromolecules, 46, 2078-2091. https://doi.org/10.1021/ma400302j

[17] Goto, H. (2014) Asymmetric Polymerisation in Liquid Crystals and Resultant Electro-Chiroptical Effect: Structure Organising Polymerisation and Chiral Charge Carrier "Chiralion". IOP Conference Series: Materials Science and Engineering, 54, Article ID: 012013.

[18] Goto, H. (2003) Original Fundamental Ideas and the First Experiments. Archive of Research Laboratory Note, University of Tsukuba.

http://www.ims.tsukuba.ac.jp/ gotoh_lab/Note\%20Goto.pdf

\section{Scientific Research Publishing \\ Submit or recommend next manuscript to SCIRP and we will provide best service for you:}

Accepting pre-submission inquiries through Email, Facebook, LinkedIn, Twitter, etc. A wide selection of journals (inclusive of 9 subjects, more than 200 journals)

Providing 24-hour high-quality service

User-friendly online submission system

Fair and swift peer-review system

Efficient typesetting and proofreading procedure

Display of the result of downloads and visits, as well as the number of cited articles

Maximum dissemination of your research work

Submit your manuscript at: http://papersubmission.scirp.org/

Or contact msce@scirp.org 